Original article

\title{
EFFECT OF TOPICAL USE OF TRANEXAMIC ACID IN PATIENTS WITH THORACOLUMBAR FRACTURE UNDERGOING POSTERIOR SPINAL FIXATION AND FUSION
}

\author{
Mohamed Abdel Wanis, Ahmed Sleem ${ }^{(*)}$, Mostafa Abdel-all \\ Orthopedic Surgery dept., Faculty of Medicine, Sohag University, Sohag, Egypt \\ *E-mail: asaleh1975@yahoo.com
}

\begin{abstract}
Thoracic and lumbar spine trauma (TLST) is frequently associated with chest and abdominal injuries. Multilevel spinal fusions require a longer operative time, with significant soft tissue stripping as well as blood loss, which frequently leads to allogenic blood transfusion. Topical TXA might enhance patient safety, reducing excessive postoperative bleeding. To evaluate effect of topically applied $1 \mathrm{~g}$ TXA on postoperative whole blood transfusion and blood loss in neurologically intact patients with thoracolumbar spine fracture. A clinical prospective randomized study is done on 30 patients with thoracolumbar fracture, undergoing primary posterior instrumented fixation and fusion. Patients were randomized to 2 groups, first group (15 patients) was injected with saline only and second group (15 patients) was injected with mixture of tranexamic acid and saline. Patients were operated under general anesthesia, using a standard midline incision. Wounds are closed in layers over a 16 gauge suction drain; injection cocktail was delivered retrograde into the drain which was then closed for 2 hours. There was a highly significant decrease in blood loss in Group 2. The decrease in Hb level is less in the $2^{\text {nd }}$ group than in the $1^{\text {st }}$ group, indicating less postoperative anemia in the blood count (highly significant). Use of topically administered $1 \mathrm{~g}$ of TXA $(20 \mathrm{~mL})$ in thoracic and lumbar spinal trauma cases undergoing posterior instrumented fixation and fusion effectively decreased postoperative transfusion requirements. Treatment also reduced total drainage volume, time until drain removal, and length of postoperative hospital stay.
\end{abstract}

Keyword: Tranexamic acid, Thoracolumbar fracture, Posterior spinal fixation and fusion

\section{Introduction}

Thoracic and lumbar spine trauma (TLST) usually results from a high energy injury and is frequently associated with chest and abdominal injuries [1]. Mechanically unstable spinal injuries are commonly noted following severe spine trauma, and they often require surgical stabilization due to a high risk of neurological decline [2]. Operative intervention for patients without neurological deficits should be considered if the Thoracolumbar
Injury Classification and Severity (TLICS) score exceeds 4 points [3]. Multilevel spinal fusions require a longer operative time, with significant soft tissue stripping as well as blood loss, which frequently leads to allogeneic blood transfusion [4]. In particular, the economic disadvantage associated with significant iatrogenic blood loss contributes to the direct costs of blood product usage. Moreover, indirect costs, including those associated with pro- 
longed hospitalization, are often involved in the management of this complication [5]. Several interventions have been used to reduce surgical blood loss and the need for transfusion, including acute normovolemic hemodilution and various blood salvaging techniques [6]. Additionally, antifibrinolytic agents have been used in various studies to control acute hemorrhage and decrease transfusion requirements in patients undergoing surgical treatment [7]. Additionally, antifibrinolytic agents have been used in various studies to control acute hemorrhage and decrease transfusion requirements in patients undergoing surgical treatment [8]. This is especially important in multilevel spinal fusion procedures with instrumentation, which often require postoperative blood transfusion [9]. Even though intravenous

\section{Patients and Methods}

This prospective double-blinded randomized controlled trial was conducted at sohag university hospita. The study was conducted from June 2018 till June 2019. The study has included 30 patients
TXA has been shown to reduce excessive postoperative bleeding, it is unclear whether the effects of this drug can be escalated, potentially resulting in thromboembolic events and cardiovascular complications (e.g., pulmonary embolism, deep venous thrombosis, and myocardial infarction) $[9,10]$. Topical TXA might enhance patient safety, as similar effects via an intravenous route were reported in another study [11]. The present study examined topical application of tranexamic acid (TXA) compared with normal saline placebo in cases with thoracolumbar spine fracture undergoing posterior instrumented fixation and fusion that include cases with complete burst and flexion distraction injury (A4 and B fracture according to AO classification of thoracolumbar spine fracture).

randomized into 2 groups, 15 patients topically injected with Tranexamic acid and saline and 15 patients topically injected with saline only, fig. (1).

Figure (1) Shows study design

\subsection{Inclusion criteria}

1) Men and women, 18 to 70 years of age with injuries involving the thoracic or lumbar spine (type A4 and type $\mathrm{B}$ according to $\mathrm{AO}$ classification and TLICS score $>5$ ) undergoing instrumented

\subsection{Exclusion criteria}

1) Renal insufficiency, 2) History of thromboembolic events, 3) History of significant cardiovascular diseases, 4) Coagulation disorder, 5) Allergy to posterior spinal fusion with local autologous bone graft which was harvested from spinous process and decortication. 2) No neurological deficits.

tranexamic acid, 6) History of aspirin or nonsteroidal anti-inflammatory drug intake within a week before randomization and during the hospitalization. 


\subsection{Methods}

I) History taking; detailed history was obtained about the patients' mechanism of injury. 2) Clinical examination; All patients had full examination for neurological deficit and if there is associated fractures. 3) Laboratory investigations; Preoperative full laboratory investigation is done for all patients; complete blood count, prothrombin time, partial thromboplastin time, INR, fasting and post-

\subsection{Surgical technique}

I) Anesthesia; all patients were operated under general anesthesia. II) Surgical technique; a standard midline incision with posterior open approach; midline approach, fig. (2). Standard techniques of intraoperative hemostasis used. All burst fracture with Thoracolumbar Injury Classification and Severity score $\geq 5$ managed by posterior instrumented fixation and fusion, fig. (3). The components of the mixture delivered in the

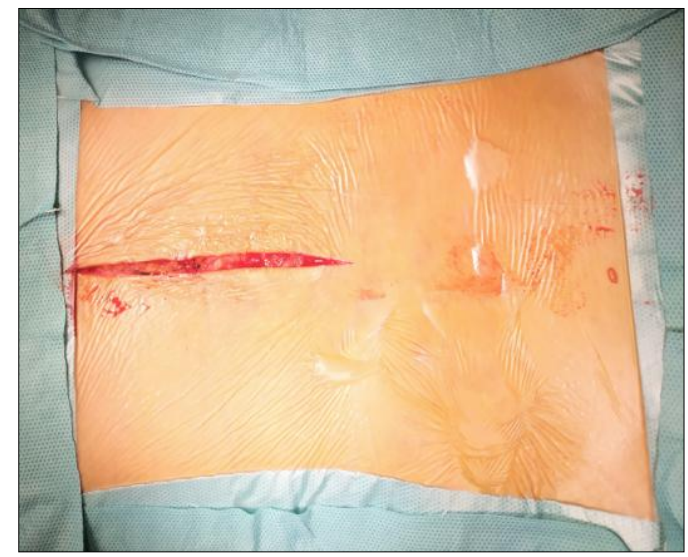

Figure (2) Shows midline incision of the back with posterior midline approach prandial blood sugar, ALT, AST and kidney functions were done. 4) Radiographic evaluation; All the patient had done plain radiography of the affected regions in the anteroposterior and lateral projections. All patients also underwent a preoperative computed tomographic scan of the thoracic and lumbar areas with multiplanar reconstructions.

redivac are: $1000 \mathrm{mg}$ tranexamic acid (kapron -Egyptian market- 2 ampules 500 $\mathrm{mg}$ each) total $10 \mathrm{ml}$ and $40 \mathrm{ml}$ normal sterilized saline. Total volume of the Mixture was mixed inside sterilized surgery dish then it was injected using $50 \mathrm{ml}$ syringe into the drain in the second group, fig. (4). But, for the first group (control), they were injected by $50 \mathrm{ml}$ normal saline only.

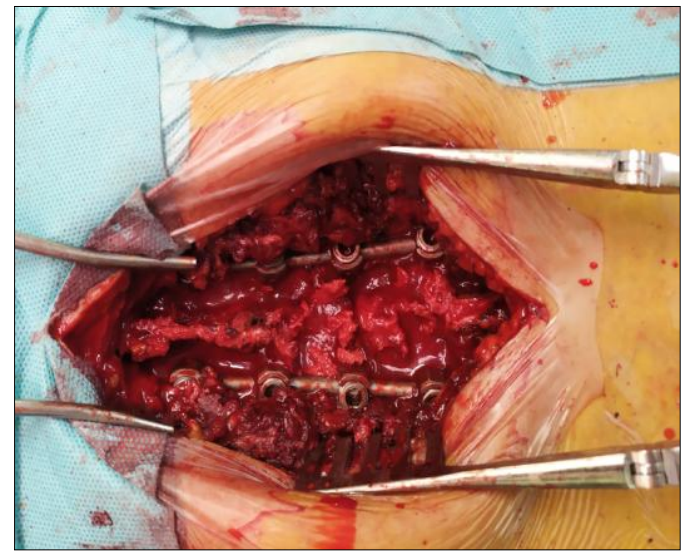

Figure (3) Shows burst fracture managed by posterior transpedicular fixation and fusion

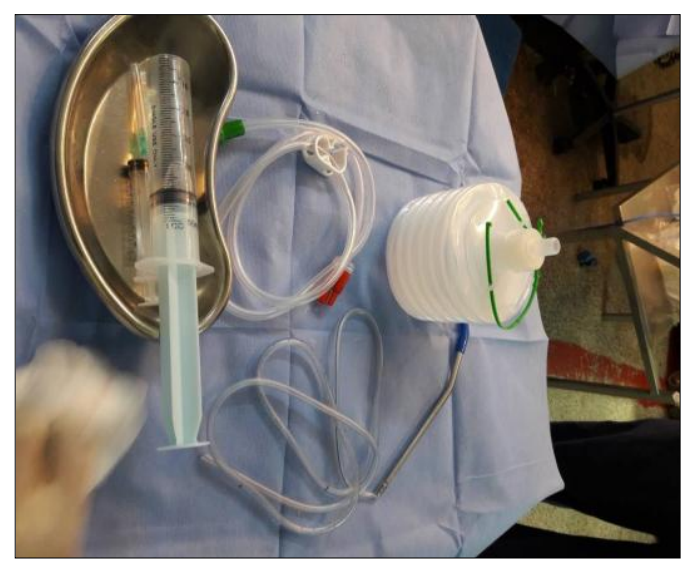

Figure (4) Shows mixture is ready to deliver and redivac drain 16 gauge is prepared 


\subsection{Postoperative evaluation}

Complete blood count was done 48 hours after surgery to evaluate $\mathrm{Hb}$ level postoperatively. Total draining fluids in

the drain are documented for 48 hours according to recorded amount in the patient file, fig. (5).

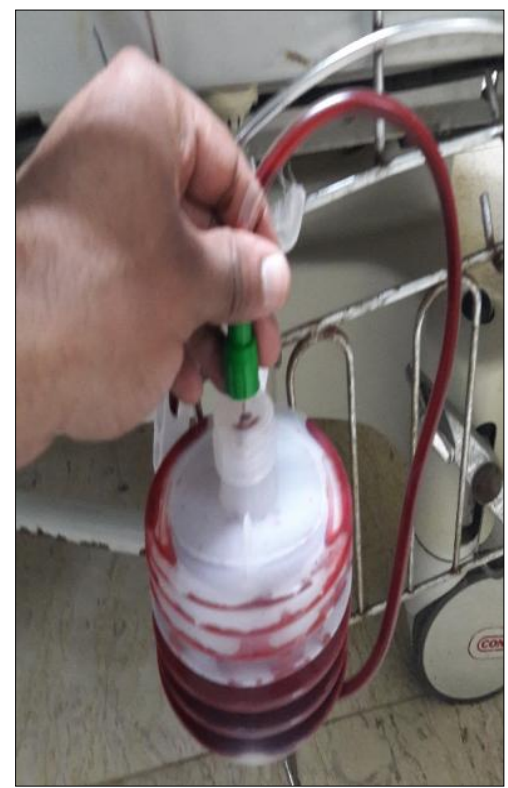

Figure (5) Shows drain reading 48 hours postoperatively

\subsection{Statistical analysis}

Data were analyzed using Statistical Program for Social Science (SPSS) version 20.0. Quantitative data were expressed as mean \pm standard deviation (SD). Qualitative data were expressed as frequency and percentage. The following tests were done: 1) Independent-samples t-test of significance was used when comparing between two means. 2) Paired sample t-

\section{Results}

Table (1) shows that the female $(63.3 \%)$ and male $(36.7 \%)$, also age ranged 33-52 with mean 39 \pm 4.95 ; body mass index ranged $22,2 \pm 3.3\left(\mathrm{~kg} / \mathrm{m}^{2}\right)$, according to TLICS score $(76.6 \%)$ had score 5, (3.3\%) had score 6, (20.1\%) had score 7; according to mechanism of injury $(63.3 \%)$ falling from height, $(13.3 \%)$ had motorcycle accident, (16.6\%) had motor vehicle accident, $(6,6 \%)$ had stuck a heavy object; according to fractured vertebra, $(6,6 \%)$ had fracture T11, (20\%) had fracture T12, $(53.3 \%)$ had fracture L1, (20\%) had fracture L2. Table (2) shows no statistically significant difference between groups according test of significance was used when comparing between related samples. 3) Chisquare $\left(\mathrm{X}^{2}\right)$ test of significance was used in order to compare proportions between two qualitative parameters. 4) Probability (P-value), where, *) P-value $\leq 0.05$ was considered significant. *) P-value $\leq 0.001$ was considered as highly significant. *) Pvalue $>0.05$ was considered insignificant.

to age and gender data. Table (3) shows no statistically significant difference between groups according to TLICS score, mechanism of injury and fractured level. Table (4) shows highly statistically significant difference between preoperative and postoperative according to $\mathrm{Hb}$ in each group. Also, the decrease in $\mathrm{Hb}$ level is less in the $2^{\text {nd }}$ group than in the $1^{\text {st }}$ group which indicate less postoperative anemia in the blood count. $\mathrm{P}$ value was highly significant. Table (5) shows highly statistically significant difference between groups according to total redivac drainage in $\mathrm{CC}$. 
Table (1) Description of parameters in the study group

\begin{tabular}{|c|c|}
\hline & No. $(\%)[\mathrm{N}=30]$ \\
\hline $\begin{array}{ll}\text { Sex } & \\
& \text { - Female } \\
& \text { - Male }\end{array}$ & $\begin{array}{l}19(63.3 \%) \\
11(36.7 \%)\end{array}$ \\
\hline Age (years) [Range (Mean \pm SD)] & {$[33-58(50 \pm 2.5)]$} \\
\hline Body mass index & $22,2 \pm 3.3(\mathrm{~kg} / \mathrm{m} 2)$ \\
\hline $\begin{array}{l}\text { Thoracolumbar injury classification and severity score } \\
\begin{aligned}- & 5 \\
- & 6 \\
- & 7\end{aligned}\end{array}$ & $\begin{array}{c}23(76.6 \%) \\
1(3.3 \%) \\
6(20.1 \%)\end{array}$ \\
\hline $\begin{array}{l}\text { Mechanism of injury } \\
\text { - Falling from height } \\
\text { - Motorcycle accident } \\
\text { - Motor vehicle accident } \\
\text { - Stuck a heavy object }\end{array}$ & $\begin{array}{l}19(63.3 \%) \\
4(13.3 \%) \\
5(16.6 \%) \\
2(6.6 \%)\end{array}$ \\
\hline $\begin{array}{l}\text { Fractured level } \\
\qquad \begin{array}{l}\text { - T11 } \\
\text { - T12 } \\
\text { - L1 } \\
\text { - L2 }\end{array}\end{array}$ & $\begin{array}{l}2(6.6 \%) \\
6(80 \%) \\
16(53.3 \%) \\
6(20 \%)\end{array}$ \\
\hline Preoperative Hb [Range $($ Mean \pm SD $)]$ & {$[12.2-15(13.21 \pm 0.73)]$} \\
\hline Postoperative Hb [Range (Mean \pm SD)] & {$[9.4-12.5(10.77 \pm 0.88)]$} \\
\hline Total Redivac Drainage in CC [Range (Mean+SD)] & {$[200-1450(799.33 \pm 493.07)]$} \\
\hline
\end{tabular}

Table (2) Comparison between group I and group II according to demographic data

\begin{tabular}{|l|c|c|c|}
\hline Demographic Data & Group I & Group II & p-value \\
\hline Age (years) & & & \\
- Mean & 51.5 & 52 & 0.45 \\
- Range & $33.5-58$ & $33.5-55.5$ & \\
\hline Sex & & & 0.25 \\
- Female & $11(73.3 \%)$ & $8(53.3 \%)$ & \\
- Male & $4(26.7 \%)$ & $7(46.7 \%)$ & 0.87 \\
\hline Body mass index & $22.3 \pm 3.2$ & $22.2 \pm 3.3$ & \\
\hline
\end{tabular}

Table (3) Comparison between group I and group II according to TLICS, mechanism of injury and fractured level

\begin{tabular}{|l|c|c|c|}
\hline & Group I & Group II & p-value \\
\hline Thoracolumbar injury classification and severity score & & & \\
(TLICS) & $12(80 \%)$ & $11(73.3 \%)$ & 0.12 \\
- 5 & $0(0 \%)$ & $1(6.7 \%)$ & \\
- 6 & $3(20 \%)$ & $3(20 \%)$ & \\
- 7 & & & \\
\hline Mechanism of injury & $10(66.3 \%)$ & $9(60 \%)$ & \\
- Falling from height & $2(13.3 \%)$ & $2(13.3 \%)$ & 0.98 \\
- Motorcycle accident & $3(20 \%)$ & $2(13.3 \%)$ & \\
- Motor vehicle accident & $1(6.4 \%)$ & $1(6.4 \%)$ & \\
- Stuck a heavy object & & & \\
\hline Fractured level & $1(6.4 \%)$ & $1(6.4 \%)$ & \\
- T11 & $1(6.4 \%)$ & $5(33.1 \%)$ & 0.29 \\
- T12 & $8(53.1 \%)$ & $8(53.1 \%)$ & \\
- L1 & $5(33.1 \%)$ & $1(6,4 \%)$ & \\
- L2 & & & \\
\hline
\end{tabular}


Table (4) Comparison between Preoperative and Postoperative according to $\mathrm{Hb}$ in each group

\begin{tabular}{|l|c|c|}
\hline \multicolumn{1}{|c|}{ Hb. } & Group I & Group II \\
\hline Preoperative & $12.88 \pm 0.53$ & $13.54 \pm 0.78$ \\
\hline Postoperative & $10.20 \pm 0.68$ & $11.33 \pm 0.66$ \\
\hline Paired Diff. & 2.68 & 2.21 \\
\hline Paired Sample t-test & 26.648 & 18.684 \\
\hline p-value & $<0.001$ & $<0.001$ \\
\hline
\end{tabular}

Table (5) Comparison between group I and group II according to total redivac drainage in CC

\begin{tabular}{|l|c|c|c|}
\hline \multicolumn{1}{|c|}{ Total Redivac Drainage in CC } & Group I & Group II & p-value \\
\cline { 1 - 3 } Mean \pm SD & $520,80 \pm 139.67$ & $318.67 \pm 53.57$ & \multirow{2}{*}{$<0.001$} \\
\hline Range & $316.12-687.34$ & $200-400$ & \\
\hline
\end{tabular}

\section{Discussion}

The currently available clinical data confirm that intravenous TXA during spinal surgery can reduce perioperative bleeding, but the evidence to reach a reliable conclusion regarding safety risk so far is too limited [12]. Myocardial infarction and systemic thromboembolic complications are rare but potentially life-threatening events in surgical patients receiving intravenous TXA. The theoretical concern for the risk of thromboembolism with intravenous TXA remains, which has encouraged investigations on TXA administration via a topical route The mechanism of topical application of TXA, a synthetic derivative of the amino acid lysine that has strong antifibrinolytic activity, is through binding to the bleeding surface, which is believed to inhibit local fibrinolysis only at the surgical field. TXA can block the enzymatic interaction of plasminogen/ plasmin with fibrinogen/fibrin, thereby preventing fibrin degradation and delaying clot dissolution [13]. Some trials have reported on the effect of topical TXA in spinal procedures. Krohn et al. [14] reported that $500 \mathrm{mg}$ of TXA added to the irrigation solution and suctioned away after 2 to 5 minutes of application significantly reduced blood loss in lumbar spinal fusion surgery by up to half. Luo et al. [15] reported that topical TXA reduced postoperative drain output (mean difference, $-157 \mathrm{~mL} ; \mathrm{p}<0.01$ ) and transfusion risk (risk difference, -0.18 ; $\mathrm{p}=0.28$ ) The optimal dose of TXA for reduction of postoperative blood loss has not yet been established. Previous studies showed that topical application of $500 \mathrm{mg}$ to $3 \mathrm{~g}$ of TXA reduced postoperative or total blood loss compared with placebo in patients undergoing total knee arthroplasty [16]. As reported in patients undergoing cardiac surgery, Martin et al. [17] noted that the use of high-dose TXA resulted in seizure rates that were at least 10 -fold higher than those seen with low-dose administration. The ideal technique for topical use and the optimal timing of intraoperative topical TXA application in spinal surgery have not been clearly determined. According to the pharmacodynamic and pharmacokinetic properties of TXA, the maximum plasma concentration is obtained at 30 minutes after administration, and the terminal elimination half-life is about 120 minutes [18]. In the present study, $1 \mathrm{~g}$ of topical TXA was applied to the site of surgery via a drain tube after the spinal fascia was closed, and then the drain was clamped for 2 hours. The length of time that the drain was clamped was equal to the half-life of TXA and was sufficient for the hemostatic activity of topical TXA to be exerted before the drain was unclamped [1]. A longer clamping period might cause more pain and might predispose to the formation of large hematomas, which sometimes require surgical removal. Schlag et al. [19] excluded patients who had neurological deficits that required 
decompressive surgery, for the following reasons. First, caution needs to be taken to prevent direct contact between TXA and neural tissues, because epileptic seizures were reported to develop when TXA was topically applied for surgery within or close to the central nervous system in an experimental rat model. Second, an association between dural tears and neurological deficits has been consistently reported in patients with spinal injuries [20]. For these reasons, the use of topical TXA poses a considerable risk in patients presenting with neurological deficits resulting from TLST. There were some limitations to the present study. The extent of topical TXA tissue absorption following clamping of the drain was not quantified and should be documented by collecting samples, such as serum or plasma. Subsequent analysis of hemolytic activity should be conducted and the concentration of degradation products via the drainage tube should be measured to obtain further information about the mechanism of action and systemic absorption of topical TXA. Pulmonary arteriograms and lower extremity venograms are recommended to detect thromboembolism; however, in this study clinical assessment was used to detect complications because of the relatively high cost and invasiveness of these tools. An additional limitation of this study was the mid-term follow up period (less than one year), which is inadequate to monitor potential long-term complications.

\section{Conclusion}

The use of topically administered $1 \mathrm{~g}$ of TXA $(10 \mathrm{~mL})$ in thoracic and lumbar spinal fracture cases undergoing posterior instrumented fixation and fusion effectively decreased postoperative transfusion requirements. The treatment also reduced total drainage volume.

\section{References}

[1] Sudprasert, W., Tanaviriyachai, T., Choovongkomol, K., et al. (2019). A randomized controlled trial of topical application of tranexamic acid in patients with thoracolumbar spine trauma undergoing long-segment instrumented posterior spinal fusion. Asian Spine Journal. 13 (1): 146-154.

[2] Rajasekaran, S., Kanna, R., Shetty, A. (2015). Management of thoracolumbar spine trauma: An overview. Indian J. of Orthopaedics. 49 (1): 72-82.

[3] Joaquim, A., Fernandes, Y., Cavalcante, R., et al. (2011). Evaluation of the thoracolumbar injury classification system in thoracic and lumbar spinal trauma. Spine. 36 (1): 33-36.

[4] Azhari, S., Azimi, P., Shahzadi, S., et al. (2016). Decision-making process in patients with thoracolumbar and lumbar burst fractures with thoracolumbar injury severity and classification score less than four. Asian Spine Journal. 10 (1): 136-142.

[5] Tse, E., Cheung, W., Ng, K., et al. (2011). Reducing perioperative blood loss and allogenic blood transfusion in patients undergoing major spine surgery. JBJS. 93 (13): 1268-1277.

[6] Marik, P., Corwin, H. (2008). Efficacy of red blood cell transfusion in the critically ill: A systematic review of the literature. Critical Care Medicine. 36 (9): 2667-2674.

[7] Elgafy, H., Bransford, R., McGuire, R., et al. (2010). Blood loss in major spine surgery: Are there effective measures to decrease massive hemorrhage in major spine fusion surgery? Spine. 35 (9S): S47-S56.

[8] Hofmann, A., Ozawa, S., Farrugia, A., et al. (2013). Economic considerations on transfusion medicine and patient blood management. Best Practice \& Research Clinical Anaesthesiology. 27 (1): 59-68.

[9] Ker, K., Prieto-Merino, D., Roberts, I. (2013). Systematic review, meta-analysis and meta-regression of the effect of tranexamic acid on surgical blood loss. BJS. 100 (10): 1271-9. 
[10] Badeaux, J., Hawley, D. (2014). A Systematic review of the effectiveness of intravenous tranexamic acid administration in managing perioperative blood loss in patients undergoing spine surgery. J. of Peri-Anesthesia Nursing. 29 (6): 459-65.

[11] Winter, S., Santaguida, C., Wong, J., et al. (2016).Systemic and topical use of tranexamic acid in spinal surgery: A systematic review. Global Spine J; 6(3): 284-95.

[12] Rali, P., Gangem,i A., Moores, A., et al. (2019). Direct-acting oral anticoagulants in critically Ill patients. Chest. 156 (3): 604-618.

[13] Mahdy, A., Webster, N. (2004). Perioperative systemic haemostatic agents. BJA: British J. of Anaesthesia. 93 (6): 842-58.

[14] Krohn, C., Sørensen, R., Lange, J., et al. (2003) Tranexamic acid given into the wound reduces postoperative blood loss by half in major orthopaedic surgery. Eur J Surg Suppl. 588: 57-61.

[15] Luo, W., Sun, R-X. Jiang, H., et al. (2018). The efficacy and safety of topical administration of tranexami- cacid in spine surgery: A metaanalysis. J. of Orthopaedic Surgery and Research. 13 (1): 96.

[16] Wong, J., Abrishami, A., El Beheiry, H., et al. (2010). Topical application of tranexamic acid reduces postoperative blood loss in total knee arthroplasty: A randomized, controlled trial. JBJS. 92 (15): 2503-2513.

[17] Martin, K., Wiesner, G., Breuer, T., et al. (2008). Lange R, Tassani P. The risks of aprotinin and tranexamic acid in cardiac surgery: A one-year followup of 1188 consecutive patients. Anesthesia \& Analgesia. 107 (6): 17831790.

[18] Dunn, C., Goa, K. (1999). Tranexamic acid. Drugs. 57 (6): 1005-1032.

[19] Schlag, M., Hopf, R., Zifko, U., et al. (2002). Epileptic seizures following cortical application of fibrin sealants containing tranexamic acid in rats. Acta Neurochirurgica. 144 (1): 63-69.

[20] Skiak, E., Karakasli, A., Harb, A., et al. (2015). The effect of laminae lesion on thoraco-lumbar fracture reduction. Orthopaedics \& Traumatology: Surgery \& Research. 101 (4): 489-494. 